\title{
A PBL na Universidade de Newcastle: Um Modelo para o Ensino de Engenharia no Brasil? ${ }^{1}$
}

\author{
PBL At The University of Newcastle: A \\ Model For Engineering Education In \\ Brazil?
}

\author{
Luis Roberto RIBEIRO* \\ Maria da Graça N. MIZUKAMI**
}

\begin{abstract}
RESUMO
Diferentemente dos métodos convencionais que colocam problemas de aplicação ao final da apresentação de um conteúdo, a Aprendizagem Baseada em Problemas ou PBL (Problem-based Learning) é um método instrucional que usa um problema para iniciar, motivar e focar a aquisição de conhecimentos, além de estimular o desenvolvimento de habilidades e atitudes profissionais. Este trabalho descreve e analisa a utilização da PBL na Escola de Arquitetura da Universidade de Newcastle (Austrália) e reflete sobre a viabilidade de utilização desse modelo no ensino de engenharia no Brasil. Os dados deste trabalho derivam de observação participante de um ciclo completo do método, de entrevistas não estruturadas e da análise de material produzido pela escola e pelos alunos. Os resultados sugerem ser viável a implementação de tal modelo em nossos currículos de engenharia, desde que as especificidades dessa área de conhecimento e dos diferentes contextos educacionais e institucionais sejam consideradas.
\end{abstract}

Palavras-chave: PBL - aprendizagem baseada em problemas - ensino de engenharia.

\footnotetext{
${ }^{1}$ Baseado em trabalho apresentado no XXXII COBENGE, Brasília, 14-17 de setembro de 2004.

* Mestre em Engenharia (Engenharia de Produção) pela USP. Pesquisador da Universidade Federal de São Carlos, Centro de Educação e Ciências humanas - UFSCAR. Email:luisrcr@iris.ufscar.br

${ }^{* *}$ Pós-Doutora pela Santa Clara University - Teacher Education Program, SCU, EUA. Professora da UFSCar. Professora Assistente da Universidade Estadual Paulista Júlio de Mesquita Filho - UNESP. E-mail: dmgn@power.ufscar.br
}

Olhar de professor, Ponta Grossa, 7(1): 133-147, 2004. 


\begin{abstract}
The difference of the conventional methods that set application problems at the end of a content presentation, the Learning Based on Problems or PBL (Problem-based Learning) is an instructional method that utilizes a problem to begin, to motivate and focus the knowledge acquisition, beyond stimulating the developing skills and professional aptitudes. This work describes and analyses the utilization of PBL at School of Architecture of University of Newcastle (Australia) and offers the reflection about the viability of using that pattern in the engineering teaching at Brasil. The data of this work come from the participating observation of complete cycle of the method, non-structured interviews and from the analysis of material produced by the school and students. The results suggest that is practicable the implementation of that pattern in our engineering curriculums, if the specificities of that area of knowledge and of the different educational institutional contexts were considered.
\end{abstract}

Key words: PBL - learning based in problems - engineering teaching.

Estudos recentes sobre os objetivos do ensino superior e pesquisas sobre os atributos profissionais desejáveis de engenheiros parecem convergir para a promoção simultânea de conhecimentos, habilidades e atitudes. Por exemplo, Atkins, em Tynjälä (1999) coloca como objetivos do ensino superior: a capacitação profissional e o estímulo à aprendizagem ao longo da vida dos alunos, favorecendo-lhes a compreensão dos conhecimentos gerais e específicos, o pensamento crítico e a habilidade de pensar conceitualmente; a preparação para o exercício profissional, integrando-se a teoria à prática, promovendo-lhes as habilidades interpessoais e a capacidade de refletir sobre sua própria prática; e a preparação para o mundo do trabalho em geral, desenvolvendo-se as habilidades de comunicação oral e escrita dos alunos e sua capacidade de refletir e de aprender a partir de situações práticas.

Esses objetivos são corroborados por pesquisas feitas junto a estudiosos, profissionais e empregadores (e.g. MORAES, 1999), que listam alguns atributos profissionais desejáveis de engenheiros, dentre os quais: (a) conhecimentos: ciência e tecnologia, computação, administração, impactos ambientais e sociais da tecnologia etc.; (b) habilidades: desenvolvimento de projetos, solução de problemas, comunicação, trabalho em equipe, auto-avaliação e avaliação de pares etc.; e (c) atitudes: ética, responsabilidade para com colegas, sociedade e profissão, iniciativa, flexibilidade, empreendedorismo, motivação para o aprendizado autônomo ao longo da vida, dentre outras.

É possível imaginar que as escolas de engenharia considerem importante um processo formativo que contemple uma formação integral, mas

$\overline{134}$ Olhar de professor, Ponta Grossa, 7(1): 133-147, 2004. 
permanece o desafio de operacionalizá-la: como promover a aquisição de um corpo de conhecimentos crescente, complexo e mutável, ao mesmo tempo em que se busca desenvolver outros atributos profissionais? A resposta a esse desafio não é uma tarefa simples, já que não é viável estender ou sobrecarregar os currículos. No nível da sala de aula, alguns métodos de ensino alternativos tentam responder a tal desafio, dentre eles a Aprendizagem Baseada em Problemas ou PBL (Problembased Learning), conhecida por oferecer aos alunos um meio de adquirir conhecimentos e desenvolver as habilidades e atitudes valorizadas na vida profissional sem a necessidade de disciplinas especialmente concebidas para esse fim.

\section{AAPRENDIZAGEMBASEADAEM PROBLEMAS (PBL)}

A PBL, originada na Universidade McMaster (Canadá) nos anos 1960, é um método de ensino que tem como característica principal um processo que utiliza problemas para iniciar e motivar a aprendizagem de conceitos e promover habilidades e atitudes necessárias à sua solução, diferentemente dos métodos convencionais que colocam um problema de aplicação ao final da apresentação de um conteúdo.

Embora concebida para o ensino de medicina, a PBL tem sido utilizada no ensino de outras áreas do conhe- cimento, inclusive a engenharia (e.g. WOODS, 1996; RIBEIRO et al, 2003), com as especificidades de cada área $\mathrm{e}$ a natureza do trabalho futuro de seus alunos determinando seus vários formatos. Além de ser implementada em todo o currículo, como no modelo original, a PBL também tem sido utilizada como estratégia educacional parcial, isto é, em disciplinas isoladas dentro de um currículo convencional (e.g. WILKERSON e GIJSELAERS, 1996; RIBEIRO et al, 2003) ou mesmo em partes de disciplinas (e.g. STEPIEN e GALLAGHER, 1998).

Apesar dessa variedade, todos os formatos de PBL têm em comum o fato de o problema sempre anteceder a teoria. O processo de solução original é composto do seguinte conjunto de atividades (BARROWS, 2001; ENGEL, 1998): (a) apresenta-se um problema aos alunos que, em grupos, organizam suas idéias, tentam defini-lo e solucioná-lo com o conhecimento que possuem; (b) através de discussão, levantam os aspectos do problema que não compreendem; (c) priorizam então as questões levantadas pelo grupo e planejam quem, como, quando e onde essas questões serão investigadas para serem posteriormente compartilhadas; (d) quando se reencontram, exploram as questões de aprendizagem prévias, integrando seus novos conhecimentos ao contexto do problema; e (f) depois de terminado o trabalho com o problema, avaliam a si mesmos e seus pares de modo a desenvolverem ha- 
bilidades de auto-avaliação e avaliação construtiva de colegas

Mesmo pautada nesse processo, a PBL não almeja somente a solução de problemas. Barrows (1996) sustenta que o objetivo desse método não se reduz ao desenvolvimento de um processo eficaz e eficiente de solução de problemas, mas também inclui a aquisição de uma base de conhecimentos integrada e estruturada em torno de problemas da vida real, bem como a promoção de habilidades de trabalho em grupo, a aprendizagem autônoma e atitudes tais como cooperação, ética, respeito pela opinião de outro, dentre outras.

\section{OBJETIVOS}

Este trabalho descreve uma implementação da PBL na Universidade de Newcastle (Austrália), analisa sua diferenciação com relação ao modelo original e reflete sobre a viabilidade de utilização desse modelo em currículos de engenharia no Brasil.

\section{METODOLOGIA DA PESQUISA}

A pesquisa, de natureza descritivo-analítica, foi realizada na Escola de Arquitetura da Universidade de Newcastle (EA/UN), Austrália, durante quatro semanas em 2004, compreendendo um ciclo completo da PBL (da introdução de um problema à discussão das soluções). A turma continha 70 alunos de primeiro ano, divi- dida em grupos de 12, supervisionados por um tutor (um docente da instituição ou profissional externo). Os dados foram coletados através de observação participante (dos encontros gerais, isto é, entre a turma, coordenador e tutores, e entre um tutor e seu grupo), de entrevistas não estruturadas com os tutores e alunos, e da análise de documentos produzidos para o curso, para o problema em questão e pelos alunos.

\section{RESULTADOS}

O ciclo da PBL observado revolveu em torno de um problema (projeto) denominado The Plan: Two Rooms, o qual faz parte de uma série de problemas concebidos de forma a promover conhecimentos, habilidades e atitudes. Tais problemas são trabalhados dentro de um componente curricular central denominado Design Integration (DI), que permeia todo o currículo da EA/UN. A natureza e o formato do curso foram e são pautados em informações obtidas junto a arquitetos e empregadores na Austrália e negociados junto aos órgãos responsáveis pela regulamentação de cursos superiores.

A importância do DI dentro da grade curricular cresce, ao mesmo tempo em que os projetos diminuem em número e ficam mais complexos, à medida em que se progride no currículo. Embora individuais, os projetos são progressivamente revisados e 
discutidos em grupo, sob a supervisão de um tutor.

\subsection{O trabalho com o Problema}

O primeiro encontro do ciclo observado consistiu da apresentação do problema, com a presença da turma e tutores em um espaço da escola, um amplo salão com divisórias móveis, pranchetas, mesas, sofás, cadeiras etc., que pode ser rearranjado conforme as demandas das atividades. $\mathrm{O}$ tutor-coordenador apresentou sucintamente o projeto à turma e demais tutores, colocando seus objetivos. O coordenador chamou então a 'cliente' (uma aluna do quinto ano fazendo as vezes de 'uma arquiteta atuante em Newcastle'). Ela colocou as especificações do projeto e a forma de apresentação desejada (também disponibilizadas por escrito), que deram os contornos do problema e sinalizaram os conteúdos (conhecimentos, habilidades e atitudes) a serem trabalhados nesse ciclo. A 'cliente' também respondeu às perguntas mais específicas da turma, como tipo de material preferido, cores etc., às quais improvisou respostas ou deixou-as ao critério dos alunos.

Terminada essa fase a 'cliente' retirou-se e o tutor-coordenador retomou o comando do processo, colocando algumas atividades e objetivos que a turma teria que cumprir durante o ciclo. O Two Rooms faz parte da grade do primeiro ano, embora sua contextualização varie de ano para ano (e.g. o cliente ser pode ser um dentista ao invés de uma arquiteta, e algumas especificações e o local de construção também podem diferir). Os conteúdos em cada problema derivam da negociação entre o coordenador do projeto e os professores das disciplinas (eles próprios tutores de projetos em outros anos), sobre quais conhecimentos, habilidades e atitudes devem ser trabalhados em um dado projeto, em vista dos objetivos maiores do currículo.

O primeiro encontro terminou com uma reunião entre os grupos e seu tutor, que retomou alguns pontos colocados pelo coordenador e a cliente, esclareceu algumas dúvidas sobre conceitos a serem trabalhados e tarefas a serem cumpridas nesse ciclo. Esse procedimento foi repetido nos encontros subseqüentes do DI, isto é, o tutor discutiu em grupo as idéias, estratégias, etc. dos alunos e esclareceu suas dúvidas, em um processo contínuo de construção, desconstrução e reconstrução de seus projetos.

Segundo um tutor, embora se discutam em grupo as produções individuais dos alunos, isso não compromete a originalidade e criatividade dos alunos, que podem aprender com os projetos de colegas. Em todos os momentos, apesar de se certificar sempre de que determinados conceitos e especificações foram levados em consideração durante o processo de concepção dos Two Rooms, o tutor mostrou-se aberto a todas as idéias, 
dando algumas indicações de implausibilidade, mas encorajando os alunos a correrem riscos, a serem criativos, a apostarem em idéias mais arrojadas - mesmo quando contrariam alguns requisitos da 'cliente'.

\subsection{As Atividades Complementares}

Durante o ciclo os alunos, em grupo, tiveram que cumprir algumas tarefas complementares que incluíram uma pesquisa na biblioteca universitária e visitas externas. A pesquisa objetivava o conhecimento do trabalho de arquitetos contemporâneos famosos. Uma das visitas externas consistiu na ida dos grupos a escritórios de arquitetura em Newcastle, para conhecer seu funcionamento, suas atividades, suas necessidades com relação a equipamentos, espaço, iluminação etc. Uma segunda visita foi programada à propriedade rural nas cercanias de Newcastle, onde os Two Rooms seriam construídos. A propriedade foi explorada cuidadosamente pelos alunos, que caracterizaram o terreno e o local de forma a escolherem, em grupo, o local exato da construção.

\subsection{As Disciplinas de Apoio}

Além do DI, a grade curricular dos alunos também era composta de algumas disciplinas de apoio cujos conteúdos versam sobre tópicos variados (e.g. desenho, estudos ambientais, ambiente urbano, habili- dades de comunicação relacionadas a projetos de arquitetura etc.). A alocação de tempo para essas disciplinas varia dentro de um total de 1215 horas de contato direto aluno-docente por semana (nesse ciclo foram alocadas 4,5 horas ao DI e 7,5 horas às disciplinas). Esse total, pequeno se comparado aos dos currículos de engenharia no Brasil, é fundamental para que os alunos tenham tempo para trabalhar em seus projetos e cumprir as tarefas propostas pelos docentes das disciplinas.

A natureza dos conteúdos das disciplinas e o momento de sua inserção no currículo da EA/UN são pensados de modo a informarem os problemas em andamento, porém essa integração nem sempre é possível. Segundo um tutor, a disponibilização de conteúdos sob demanda, como ocorreria em um ambiente PBL ideal, seria impossível já que a administração da escola requisita um plano de atividades com pelo menos um ano de antecedência. As disciplinas podem ter a duração semestral ou anual, mas seu número quantidade e carga horária tendem a decrescer com a progressão no currículo. Os procedimentos didáticos e formas de avaliação utilizados nessas disciplinas variam: são realizados desde seminários e aulas expositivas a palestras com profissionais convidados e oficinas.

\subsection{AAvaliação do Desempenho dos Alunos}


A avaliação discente nessa implementação da PBL é articulada de forma que o desempenho dos alunos ao final do ciclo/semestre/ano seja avaliado através da soma de várias notas dadas pelos docentes responsáveis pelas disciplinas e aquelas recebidas nos projetos e relatórios das atividades complementares. É importante ressaltar que mesmo nas atividades em grupo os alunos apresentam seus trabalhos individualmente.

Essa forma de avaliação gera um total de cerca de 12 notas durante um semestre, segundo um tutor, o qual enfatiza que a avaliação na referida instituição não está ancorada na demonstração de habilidades ou memorização de conhecimentos. Especialmente com relação ao DI, a avaliação é baseada na capacidade dos alunos de conceberem novas idéias, justificarem suas decisões, demonstrarem pensamento crítico, raciocínio etc. Os critérios para essa avaliação são determinados pelo coordenador e tutores durante os primeiros anos, porém no quinto ano são concebidos pelos próprios alunos e negociados com os tutores e a escola. A avaliação do Two Rooms, como é o caso dos primeiros anos, foi feita por dois tutores, o tutor do grupo e um tutor de outro grupo. No último ano é feita por um painel de profissionais composto por um docente e o diretor da EA/UN, um docente de outra escola de arquitetura e um arquiteto atuante.

O peso que a nota dada aos projetos tem na composição da nota final do aluno, em comparação com as notas de trabalhos de disciplinas, entre outras, varia de acordo com o ano e a complexidade do projeto. Segundo um tutor, no primeiro ano a nota de projeto compõe $25 \%$ da nota final, enquanto que no quarto ano essa proporção sobe para $50 \%$. No último ano a avaliação do projeto compõe quase que a totalidade da nota do aluno.

\section{DISCUSSÃO}

Existem vários aspectos da abordagem PBL da EA/UN que podem ser discutidos à luz do modelo original e de uma possível implementação no ensino de engenharia no Brasil. Entretanto, é necessário enfatizar que a descrição acima não deve ser tomada como uma receita de implementação desse método em escolas de engenharia, apesar de contemplar muitos dos requisitos colocados por Perrenet et al (2000) para a utilização da PBL no ensino dessa disciplina (e.g. maior direção por parte dos professores, uso de projetos de longa e curta duração etc.). É claro para os autores que esse modelo de $\mathrm{PBL}$ responde somente às necessidades e particularidades do ensino dessa área de conhecimento na escola onde foi utilizado, visto que a PBL, mesmo quando utilizada em outras escolas da própria UN, o é de maneira diversa. Ademais, como este trabalho mostrou, esse exemplo de utilização da PBL não se caracteriza como um modelo pronto e acabado.

Um dos aspectos que diferenciam 
essa utilização da PBL do modelo original é o fato de ser centrado nos professores, já que eles concebem os problemas, definem os objetivos de aprendizagem e a forma de apresentação dos resultados, e aplicam os critérios de avaliação. Outro aspecto é o fato de a PBL ser respaldada por disciplinas preestabelecidas. Tais aspectos derivam tanto das especificidades dessa área de conhecimento, na qual a solução do problema é geralmente um projeto e não um diagnóstico, como na medicina, quanto da gênese da implementação do método na referida escola, em 1983/85.

Segundo um tutor, nessa época havia consenso sobre a necessidade de uma mudança, inspirada na adoção da PBL pela escola de medicina da UN, porém desejava-se utilizar os recursos e a estrutura existentes. Assim, tornou-se a disciplina de desenvolvimento de projetos existente no currículo anterior em um componente central do novo currículo, onde se daria a solução de problemas e a integração de conhecimentos. Para isso alocou-se para essa disciplina mais tempo, subtraído das outras disciplinas, que passaram a lhe dar de suporte. Esta redução no conteúdo das disciplinas, segundo Kingsland (1993), não significou uma diminuição da qualidade, porque parte dos conteúdos foi transferida para o DI e disponibilizou-se tempo e espaço para que os alunos se dedicassem aos projetos e os docentes facilitassem esse processo. Assim, com a carga horária das disciplinas reduzida, os docentes dispuseram de mais tempo para atuar como tutores ou consultores (para os alunos) dentro de suas especializações.

Em muitos cursos de engenharia no Brasil, dependendo da instituição e carreira, o trabalho com projetos só aparece no último ano, ficando ao cargo dos alunos buscarem nesse momento a integração dos conteúdos transmitidos anteriormente de forma compartimentada, não situada e dissociada da prática. Há também outros momentos em que se objetiva alguma integração, tais como os laboratórios, mas estes acabam se resumindo a momentos de aplicação e verificação de fórmulas e conteúdos estanques, previamente ensinados. De fato, como acredita Salum (1999, p. 113), a própria existência desses componentes curriculares e dos projetos de final de curso caracteriza "uma suposição de que, individualmente ou em pequenos grupos, os conhecimentos não têm sentido".

Em uma possível implementação da PBL em currículos de engenharia no Brasil, parece que os mencionados componentes (projeto de graduação e laboratórios) podem vir a ser um componente de integração e solução de problemas. Procedendo-se de forma similar à EA/UN, pode-se valorizar o projeto de fim de curso e atribuir-lhe centralidade, alocando-lhe maior carga horária, trabalho em grupo e outras atividades no último ano e, gradualmente, torná-lo presente

$\overline{140}$ Olhar de professor, Ponta Grossa, 7(1): 133-147, 2004. 
nos anos anteriores, aproveitando as disciplinas de laboratório. No entanto, é necessário ressaltar que essa mudança gradual para a PBL não é consensual entre os professores da EA/UN: muitos acreditam-na difícil de ser atingida devido à inércia docente e institucional.

De qualquer forma, essa mudança parece contar com várias dificuldades em cursos de engenharia em geral. A própria inexistência ou carência de laboratórios (locais de integração dos conteúdos e solução de problemas por excelência), quando se compara com a disponibilidade dos hospitaisescola no ensino de medicina, é considerada como um obstáculo à implementação da PBL no ensino de algumas carreiras de engenharia (e.g. mecânica). Todavia, essa dificuldade não desencoraja Hessami e Gani (1993), que consideram a PBL mais interessante e motivadora, capaz de estimular a aprendizagem profunda, produzir engenheiros mais versáteis e preparados para a entrada na vida profissional.

Outra dificuldade está relacionada com os aspectos legais relativos à carga horária, a qual, no ensino de engenharia no Brasil, é entendida como horas de aula e laboratório. Esse entendimento, segundo Salum (1999), está baseado em uma crença, comum à época da promulgação da Resolução 48/76, de que uma carga horária alta de contato direto preservaria a qualidade do ensino, já que muitas escolas não possuíam infra-estrutura capaz de respaldar o estudo independente do aluno. Porém, hoje, mesmo depois do crescimento das instituições de ensino superior (IES) e da publicação das Diretrizes Curriculares Nacionais para os Cursos de Engenharia (MEC, 2002), que reforçam a necessidade de promover habilidades de estudo autônomo e de trabalho em grupo etc., a carga horária dos currículos continua alta.

Há pelo menos dois motivos aos quais se pode atribuir esse status quo. Um deles é a difícil negociação entre grande parte das escolas de engenharia e os institutos que provêm o ensino das ciências básicas, o que não ocorreu na EA/UN, cujas disciplinas sempre foram ministradas pelo seu próprio corpo docente. Outro obstáculo, interno às escolas, é conseguir convencer seus professores a reduzirem suas disciplinas, uma vez que muitos tendem a superestimar a relevância daquilo que ensinam. Assim, conseguir o comprometimento do corpo docente parece ser primordial nessa mudança.

$\mathrm{O}$ fato de esse método demandar integração entre os docentes também pode configurar-se como uma dificuldade, se consideramos a implementação da PBL em cursos de engenharia, ou superiores em geral, no Brasil. Sabe-se que tal diálogo é mal articulado nesse nível educacional, haja vista que os docentes via de regra concebem e ministram suas disciplinas isoladamente. De fato, observam-se poucas oportunidades e ten- 
tativas de comunicação entre os professores nas IES, quando se trata de ensino. As informações, quando compartilhadas, são geralmente pontuais e versam basicamente sobre o comportamento ou desempenho de determinados alunos ou turmas.

De qualquer forma, esse diálogo por si só já seria um grande ganho para o ensino de engenharia, independentemente do método adotado, na medida em que, segundo Mizukami et al (2002, p. 103), pode conduzir ao desenvolvimento profissional dos professores. A boa prática docente, segundo essas autoras, inclui, entre outros aspectos, saber "planejar - individualmente e em equipe - projetos curriculares, aplicar e desenvolver projetos, avaliar o ensino e tomar decisões tendo em vista sua melhoria, [...] desenvolver prática inovadora com os alunos, [...] e envolver-se permanentemente em atividades de conhecimento, melhoria e revisão da própria ação".

$\mathrm{O}$ atendimento de tais aspectos (a integração docente e outros) sinaliza que a PBL pode demandar conhecimentos, habilidades e atitudes profissionais que não são inatos à maior parte do corpo docente (LITTLE e SAUER, 1999). Esses atributos docentes tampouco são exigidos e, conseqüentemente, desenvolvidos em ambientes educacionais convencionais, indicando assim a importância da capacitação pedagógica inicial e continuada. Isso é ainda mais relevante quando se pensa no contexto do en- sino de engenharia no Brasil, onde quase a totalidade dos professores advém de bacharelados e programas de pós-graduação sem qualquer formação pedagógica e, geralmente, pauta sua prática docente em suas vivências como alunos e na experimentação (tentativa e erro), que podem gerar aprendizagens equivocadas.

Tal importância ficou evidente neste trabalho quando se observou que, apesar de promover a discussão entre os alunos e entre eles e o tutor, o método por si só não garantiu o envolvimento de todos alunos. Algumas vezes estabeleceu-se um diálogo entre o tutor e um aluno, mediado pelo seu projeto, sem a participação dos demais alunos nesta discussão. Outras vezes a discussão ficou limitada a uns trabalhos individuais, porque alguns alunos não haviam atingido as etapas do projeto que seriam discutidas para aquele encontro. Porém, é importante ressaltar que a PBL, como qualquer outro método instrucional, não é uma panacéia para todos os males do ensino convencional: sempre haverá alunos que não participam por timidez, sobrecarga de trabalho ou, mesmo, desinteresse.

A falta de capacitação docente para gerenciar ou atuar nesse método pode facilmente transformar um componente como o DI em uma aula expositiva, diminuindo os ganhos atribuídos à PBL. Mesmo pautada nas dúvidas do grupo (o que por si só já é uma vantagem significativa sobre os 
métodos convencionais), essa exposição pode comprometer a obtenção de objetivos educacionais mais amplos implícitos na PBL, entre os quais o desenvolvimento de habilidades interpessoais e comunicativas dos alunos, tais como trabalho em grupo, liderança, apreciação do trabalho de outros. Embora vistas como secundárias, essas habilidades são importantes para a atuação dos alunos de engenharia no longo prazo, uma vez que é grande a probabilidade de esses profissionais assumirem posições administrativas durante suas carreiras.

$\mathrm{O}$ mesmo se aplica às atividades e disciplinas de apoio, isto é, seu planejamento demanda grande interação entre os docentes. Embora seja possível encontrar visitas externas programadas em muitos cursos de engenharia (visitas a fábricas, empresas, locais de construção etc.), é necessário enfatizar que as visitas, nessa abordagem, demandam um planejamento mais cuidadoso, já que não são um fim em si mesmas, mas têm objetivos específicos associados à solução dos problemas em questão.

Pode-se imaginar, ainda, que o diálogo entre os docentes também seja fundamental na articulação entre o componente de solução de problemas e as disciplinas de apoio. Apesar de demandar um consenso sobre os conteúdos a serem trabalhados em um determinado ciclo para que haja a integração entre a teoria e a prática, a interação entre os docentes das dis- ciplinas na EA/UN e o coordenador do ciclo parece ser igualmente necessária durante todo o processo. Observou-se que, em pelo menos um momento do ciclo, os trabalhos pedidos pelos professores das disciplinas esvaziaram o DI. Esse fato parece indicar que sem diálogo e sem a visão compartilhada, e constantemente promovida, da centralidade desse componente, o modelo $\mathrm{PBL}$ da EA/UN pode rapidamente retroceder a um processo de ensino-aprendizagem mais convencional.

A exigência da apresentação de muitos trabalhos, além do projeto (relatórios de visitas, pesquisas em biblioteca, trabalhos das disciplinas etc.), também pode contribuir para esse retrocesso, na medida em que os alunos podem vir a adotar estratégias de sobrevivência. Tais estratégias foram observadas (apesar de restritas a alguns momentos do ciclo e com relação a alguns grupos) tanto pela baixa freqüência dos alunos no DI, quanto por demonstrarem nele maior interesse pelos requisitos de apresentação do projeto do que pela discussão em si. É desnecessário dizer que essa atitude, contrária ao princípio da PBL, que valoriza o processo mais do que os resultados, pode acabar minando a importância do diálogo (entre o tutor e o grupo, entre os alunos e entre a teoria e a prática), favorecido durante o processo de construção e desconstrução dos projetos que se estabelece nesse componente curricular.

Essa discussão também remete à 
forma de avaliação adotada pela referida instituição. A avaliação dos alunos é um ponto bastante discutido na literatura sobre PBL, pelo fato de alguns autores considerarem-na subjetiva. Aparentemente, a composição múltipla da nota final dos alunos da EA/UN, apesar de trabalhosa, concorre para a acuidade e objetividade da avaliação e facilita a avaliação do desempenho individual dos alunos, evitando a ocorrência de 'caronas'. Entretanto, pode-se imaginar que a apresentação individual de projetos desestimule o desenvolvimento de habilidades de trabalho em grupo freqüentemente citadas em pesquisas de perfis desejáveis de engenheiros, tais como brainstorming, colocação e defesa de idéias, respeito por opiniões diversas, análise de alternativas, construção de consenso, tomada de decisões compartilhadas, auto-avaliação e avaliação de pares.

A forma de avaliação usada na EA/ UN parece estar pautada em uma idéia de atuação centrada na imagem clássica do arquiteto trabalhando individualmente. Essa concepção pode coincidir com alguns contextos de atuação de um engenheiro civil, por exemplo, mas não corresponder ao trabalho normalmente realizado por engenheiros mecânicos ou de produção etc. no Brasil. Dependendo do tipo de trabalho que se imagina para o engenheiro, talvez seja interessante haver uma combinação de projetos individuais e coletivos (com grupos menores, 4-5 alunos). É importante en- tender que nesse método, todos os aspectos - desde o problema até a avaliação - devem ser pensados de forma a refletir a atuação profissional futura dos alunos.

\section{CONCLUSÃO}

Apesar de haver pontos que precisam ser aprimorados, a longa história da implementação da PBL na EA/ UN e seu prestígio atestam o sucesso de seu modelo. Esse sucesso tem origem na percepção, à época da implementação, de que uma mudança era necessária e, portanto, contou com o comprometimento de docentes e administração desde o princípio. A valorização do ensino, nessa instituição, também foi e continua sendo um fator importante de manutenção e aprimoramento de tal modelo. Esse aspecto é particularmente relevante em contextos, comuns no ensino superior no Brasil, em que a pesquisa é sobrevalorizada e o ensino é visto como um 'mal necessário'.

De fato, a combinação desses dois fatores, isto é, a percepção da necessidade de mudança e a valorização do ensino, parece ser indicativa de sucesso, já que pode contribuir para a superação das dificuldades da fase inicial da implementação e a aderência aos princípios e procedimentos do método em fases subseqüentes. Sem esses fatores, uma vez terminada a fase da novidade e confrontados com o aumento de dedicação exigido pela PBL, é provável que os atores do pro-

$\overline{144}$ Olhar de professor, Ponta Grossa, 7(1): 133-147, 2004. 
cesso (administradores, professores, alunos) tendam a retornar à sua prática anterior, acomodando-a à nova abordagem, que passa a existir somente no nível do discurso institucional.

Ademais, esses dois fatores parecem estar intimamente ligados entre si, ou seja, o descomprometimento com relação ao ensino pode levar à ausência de um processo de autoavaliação sistemática por parte dos docentes e instituição e, consequentemente, à percepção equivocada de que seu processo de ensino-aprendizagem não precisa ser melhorado. Tal equívoco, além de demonstrar desequilíbrio no atendimento do princípio que rege as atividades de uma IES, isto é, a indissociabilidade entre ensino e pesquisa, também revela que o constante questionamento e aprimoramento, valorizado nas atividades de pesquisa através do método científico, está sendo negligenciado nesta função primária da universidade: o ensino.

Sobretudo, o sucesso da implementação da PBL ou de outros métodos parece depender muito da capacitação dos atores para atuarem nesse modelo. Inclui a preparação dos administradores, professores e alunos, que geralmente vêm de um processo de escolarização baseada na recepção passiva de conhecimentos. O comprometimento institucional com o ensino e com a utilização da PBL também deve ser direcionado para a formação pedagógica inicial e continuada de seu corpo docente. Este tra- balho parece mostrar que a atuação nesse modelo per si não garante que um professor atue eficazmente dentro dos princípios desse método instrucional.

De qualquer maneira, embora não se apresentando como um modelo acabado, a abordagem à PBL da Escola de Arquitetura da Universidade de Newcastle parece ser um modelo viável para cursos de engenharia. Além das semelhanças entre o ensino dessas duas áreas de conhecimento, o que torna esse modelo interessante para o ensino de engenharia no Brasil é o fato ter sido concebido e implementado de modo a evitar estresse institucional e individual, partindo-se da estrutura existente. Ademais, a riqueza dos projetos apresentados pelos alunos ao final do ciclo observado neste trabalho atesta, apesar de suas falhas e dificuldades, relevância da abordagem à Aprendizagem Baseada em Problemas - PBL.

\section{AGRADECIMENTOS}

Aos membros da Escola de Arquitetura da Universidade de Newcastle e à CAPES, pelo apoio financeiro através do PDEE.

\section{REFERÊNCIAS}

BARROWS, H. S. Problem-based learning in medicine and beyond: a brief overview. In: WILKERSON, L.; GIJSELAERS, W. H. (Eds.). Bringing problem-based learning to higher 
education: theory and practice. San Francisco: Jossey-Bass, 1996. p. 3-12.

BARROWS, H. S. (2001). Problem-based learning (PBL). Disponível em: < http:// www.pbli.org/pbl/ > . Acesso em: 16 jun. 2001.

ENGEL, C. E. Not just a method but a way of learning. In: BOUD, D.; FELETTI, G. (Eds.). The challenge of problem-based learning. Londres: Kogan, 1998. p. 17-27.

HESSAMI, M. A.; GANI, R. Using problem-based learning in the mechanical engineering degree. In: RYAN，G. (Ed.). Research and development in problem-based learning. Sydney: University of SydneyMacArthur, 1993. p. 75-82.

KINGSLAND, A. Problem-based learning: efficient, affordable, and stress-free implementation. In: RYAN, G. (Ed.). Research and development in problem-based learning. Sydney: University of Sydney-MacArthur, 1993. p. 311-319.

LITTLE, S.E.; SAUER, C. Organizational and institutional impediments to a problem-based approach. In: BOUD, D.; FELETTI, G. (Eds.). The challenge of problem-based Learning. Londres: Kogan, 1999. p. 8188.

MEC. Diretrizes curriculares nacionais para os cursos de engenharia. Disponível em: < http://www.mec.gov.br >. Acesso em: 20 jun. 2002

MIZUKAMI, M.G.N. et al. Aprendizagem da docência: pesquisas e especificidades metodológicas. São Carlos: EdUFSCar, 2002.

MORAES, M. C. O perfil do engenhei- ro dos novos tempos e as novas pautas educacionais. In: VON LINSINGEN, I. et al. (Orgs.). Formação do engenheiro: desafios da atuação docente, tendências curriculares e questões contemporâneas da educação tecnológica. Florianópolis: EdUFSC, 1999. p. 53-66.

PERRENET, J. C. et al. The suitability of problem-based learning for engineering education: theory and practice. Teaching in Higher Education, v. 5, n. 3, p. 346-360, 2000.

RIBEIRO, L. R. C. et al. Aprendizagem baseada em problemas (PBL): uma experiência no ensino de engenharia sob a ótica dos alunos. Revista de Ciências Humanas, v. 3, n. 2, p. 95101, 2003.

SALUM, M. J. G. Os currículos de engenharia no Brasil: estágio atual e tendências. In: VON LINSINGEN, I. et al. (Eds.). Formação do engenheiro: desafios da atuação docente, tendências curriculares e questões contemporâneas da educação tecnológica. Florianópolis: EdUFSC, 1999. p. 106-116.

STEPIEN, W.; GALLAGHER, S. Problem-based learning: as authentic as it gets. In: R. FOGARTY, R. (Ed.). Problem-based learning: a collection of articles. Arlington Heights: SkyLight, 1998. p. 43-49.

TYNÄLÄ，P. Towards expert knowledge? A comparison between a constructivist and a traditional learning environment in the university. Int. Journal of Educational Research, v. 31, p. 357-442, 1999.

WILKERSON, L.; GIJSELAERS, W. H. Bringing problem-based learning to higher education. San Francisco: Jossey-Bass, 1996. 
WOODS, D. Problem-based learning for large classes in chemical engineering. In: WILKERSON, L.; GIJSELAERS, W. H. (Eds.). Bringing problem-based learning to higher education. San Francisco: Jossey-Bass, 1996. p. 91-99. 